\title{
GIS
}

Bruxelas, Bélgica

CRISTINA ROSAL

\section{SILÊNCIO QUE SE VAI \\ CANTAR O FADO...}

figura 1

Brito (1994, capa)

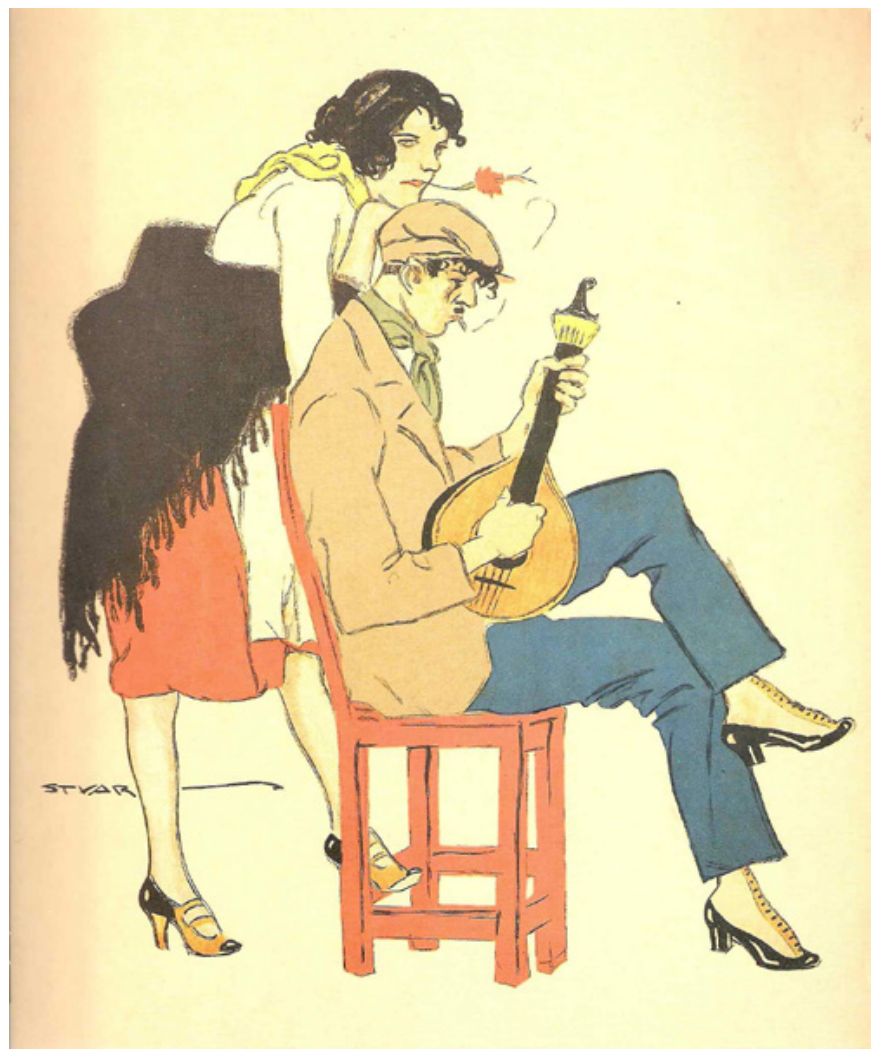

Segundo Vieira Nery $(2004,17)$, “O primeiro aspecto a constatar na procura das raízes históricas do Fado é a de que até ao final do século XVIII não conhecemos uma única fonte escrita portuguesa em que esta palavra seja utilizada com qualquer conotação musical".

Antes do início do século XIX a palavra Fado era unicamente utilizada com o significado da sua raiz latina fatum - o destino, a sina. Com esse significado, aparece em textos de poetas e escritores, como exemplo, o belíssimo poema de Luís de Camões (1524-1580/ Camões, 1994, 123): 
Com que voz chorarei meu triste fado, que em tão dura paixão me sepultou. Que mor não seja a dor que me deixou o tempo, de meu bem desenganado

Ou como este outro de Bocage (1765-1805/ Bocage, 1968, 378):

Mas no bojo voraz da desventura, Monstro por cujas fauces fui tragado Em parte um pensamento a dor me cura o infeliz (não por culpa, só por fado) Naqueles corações em que há ternura É mais interessante, é mais amado

As primeiras referências à palavra Fado associadas à música foram descritas no início do século XIX por estudiosos que visitaram o Brasil na época.

O geógrafo veneziano Adriano Balbi (1822), citado por Nery $(2004,19)$, considera que "O chiú, a chula, o fado e volta e meio são as danças mais comuns e mais notáveis do Brasil".

figura 2

Nery $(2004,28)$

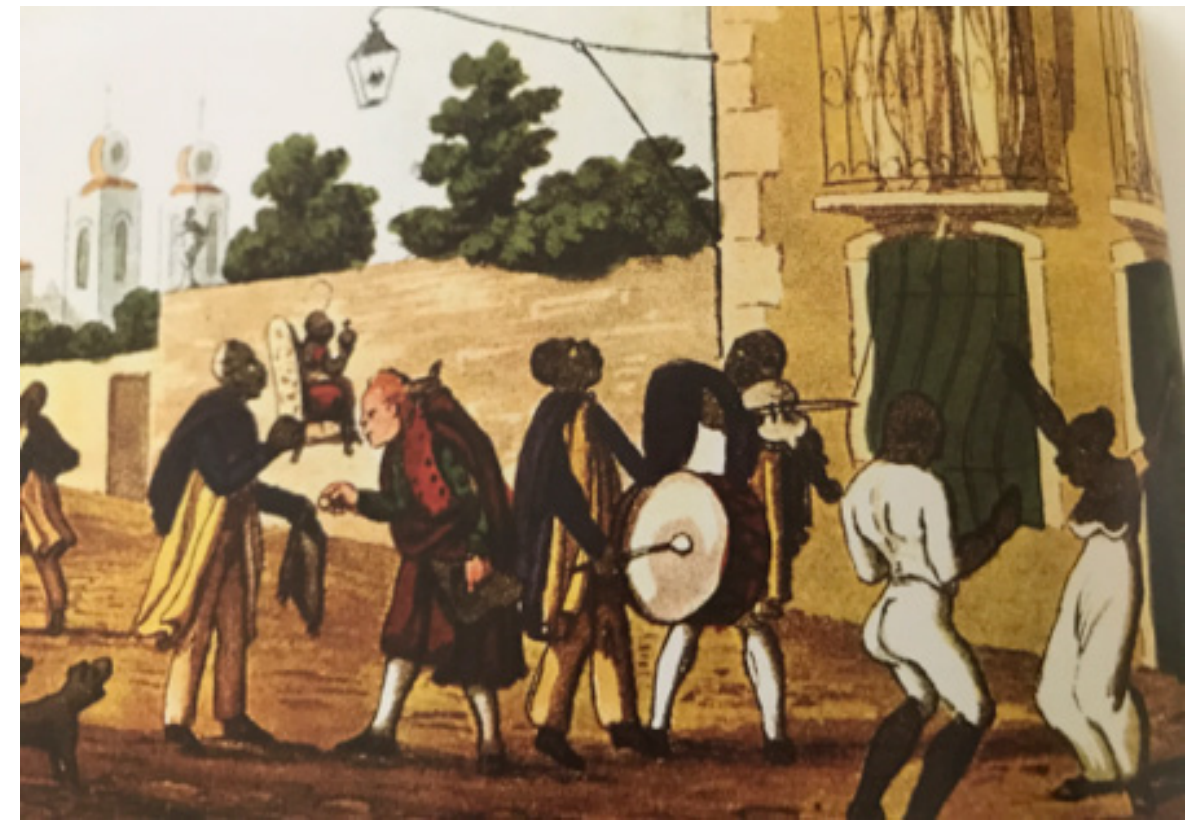

Igualmente citado por Nery (2004, 19), o francês Louis-Charles Frecynet (1827) refere que "Há cinco ou seis [danças] que são muito características: O Lundum é a mais indecente: vêm depois o carangueijo e os fados [...]. Por vezes são entremeadas de melodias cantadas muito livres. Há nelas figuras de vários géneros, todas elas muito voluptuosas". 
Ainda, Nery $(2004,20)$ cita o alemão Carl Schlichthorst (1829), que sublinha: "A dança favorita dos pretos chama-se Fado. Consiste num movimento que faz ondular suavemente e tremer o corpo, e que exprime os sentimentos mais voluptuosos da pessoa de uma maneira tão natural como indecente".

\section{O FADO DE LISBOA}

Não pretendo debruçar-me sobre as origens do fado: esse é um tema que alimenta teses muito diversas e que suscita grande controvérsia. Que elas se situem em África, no mundo árabe, no Brasil, ou nas comunidades litorais de Portugal continental, não o posso dizer. Não sou nem musicóloga, nem historiadora. Sou uma cantadeira que adora cantar e falar do fado como se de um amigo fosse. Para além disso, parece-me mais pertinente, no contexto em que nos encontramos, falar do fado ele mesmo: do seu enquadramento social desde que existe; das suas características mais marcantes; dos conteúdos cantados; da base musical e dos instrumentos utilizados; dos fados tradicionais e da improvisação. Ou seja, com a experiência que tenho, tentarei explicar como acontece a estranha consistência de uma música que todos os portugueses reconhecem como sua, que o mundo inteiro reconhece como portuguesa.

Joaquim Pais de Brito $(1994,15)$ relembra-nos que:

Fernando Pessoa (1888-1935), em resposta ao inquérito conduzido pelo Notícias Ilustrado junto de intelectuais e artistas, em 1929, esboça a seguinte formulação poética de aproximação ao fado: "O fado não é alegre nem triste. É um episódio de intervalo. Formou-o a alma portuguesa quando não existia e desejava tudo sem ter força para o desejar (...)/ o fado é o cansaço da alma forte, o olhar de desprezo de Portugal ao Deus em que creu e que também o abandonou. / No fado os deuses regressam, legítimos e longínquos". No seu hermetismo, esta sequência de imagens contem já alguns dos sinais de pertença que acompanham o fado nas práticas e representações que sobre ele se projectam - destino, alma portuguesa, cansaço, desejo, proximidade da tristeza -, sem no entanto deixar de revelar o que de pluralidade, incerteza, variação, profundidade temporal e dimensão cultural e social acompanha este fenómeno.

o Fado emergiu em Lisboa como forma musical reconhecível. Os portos de mar sempre foram lugares de partida e de chegada de pessoas e mercadorias. Nos mesmos barcos vinham também outras culturas, outras sonoridades, outras músicas. Em Lisboa, o som do lundum e das modinhas pairava. Era a fusão musical do chegar e do partir. 
Segundo Nery (2012, resumo):

A história do Fado português é um longo processo de trocas interculturais. No contexto multicultural do Brasil colonial, os ritmos e os padrões de dança africanos combinam-se com as harmonias e as formas europeias para gerar uma dança cantada de forte sensualidade que atravessa o Atlântico para se implantar nos bairros populares do porto de Lisboa. A interação entre o modelo brasileiro e as tradições locais da canção portuguesa leva gradualmente a um desaparecimento do elemento de dança e à atenuação do ritmo sincopado original, que dão agora lugar a uma atmosfera nostálgica e lamentatória, com um forte rubato na declamação do poema.

As primeiras referências ao fado de Lisboa remontam às décadas de 1820 e 1830. Em 26 de julho de 1820 nasce Maria Severa Onofriana (1820-1846) o fado ganha, então, a sua emblemática "figura fundacional": a Severa.

figura 3

Brito $(1994,142)$

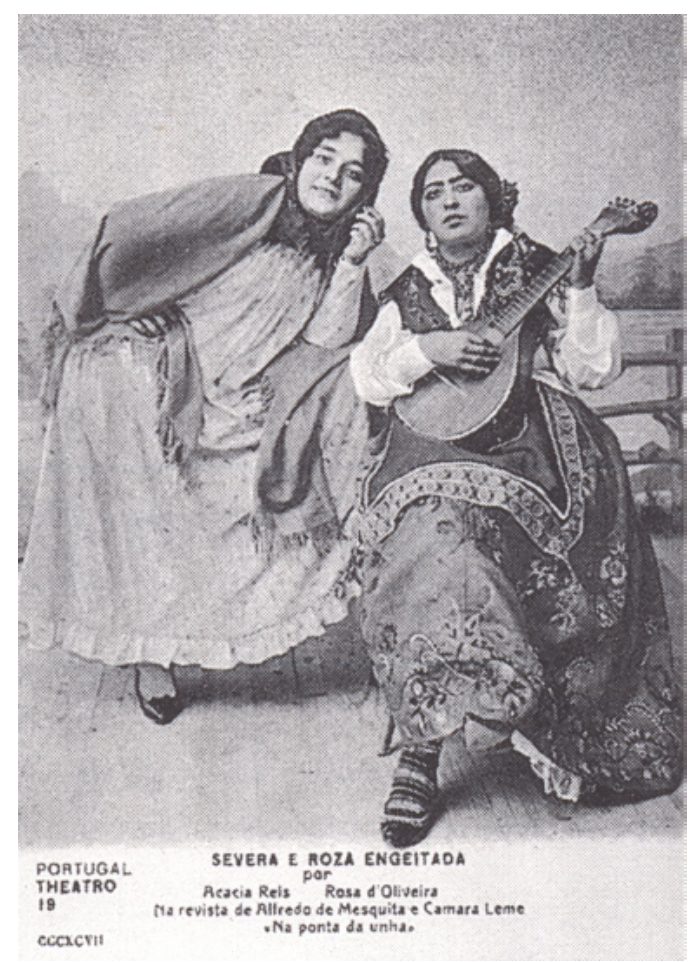

Severa, prostituta de profissão, e consagrada pelos seus dotes de cantadeira, transformou-se numa das personagens míticas da história do fado. Foi uma representante significativa do ambiente a que o fado estava associado numa primeira fase: à prostituição, com todo o ambiente social e espacial, às tavernas, às casas de passe, ao marujo, ao vagabundo, ao proxeneta e ao fadista, que se integrava perfeitamente neste contexto. 
Este estava associado à imoralidade, à marginalidade - um canalha.

figura 4

Nery $(2004,223)$

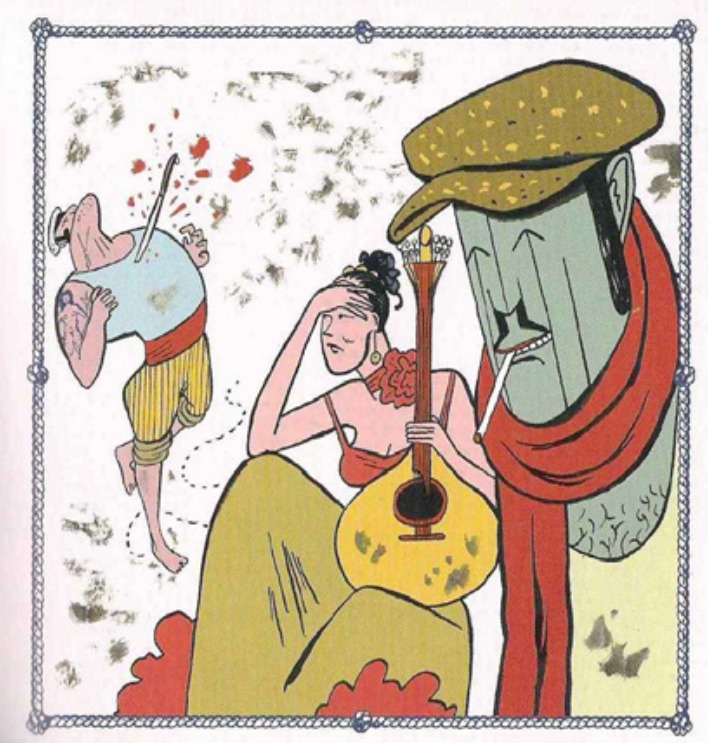

O fado aparece no grupo mais pobre da população, sem trabalho regular nos bairros mais antigos e degradados, quase labirínticos, onde a falta de luz permitia esconder a marginalidade.
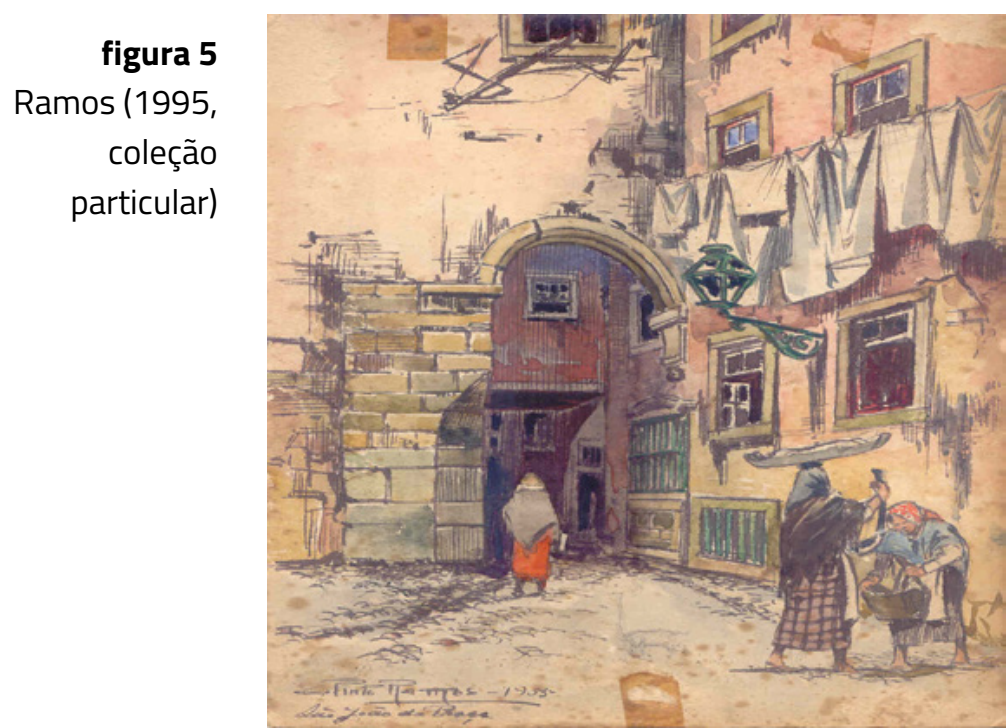

As letras dos fados eram transmitidas oralmente e tinham como objecto os episódios da vida quotidiana marginal: os crimes, as mortes anunciadas, as catástrofes naturais, assim como a vida do bairro ou os males de amor. 
Com uma estrutura melódica muito simples, o fado valorizava a interpretação de quem cantava/contava, apelando à comunhão entre o intérprete, músicos e ouvintes. Daí a frase que ainda hoje ouvimos: "É tão fadista quem canta como quem ouve!"

Entre o fado em tom menor chorado e triste (figura 6) e o ritmo veloz, irónico e brejeiro do fado corrido (figura 7), com quadras e quintilhas ou sextilhas e decassílabos, a poesia popular tinha o seu lugar e acontecia o fado.

figura 6

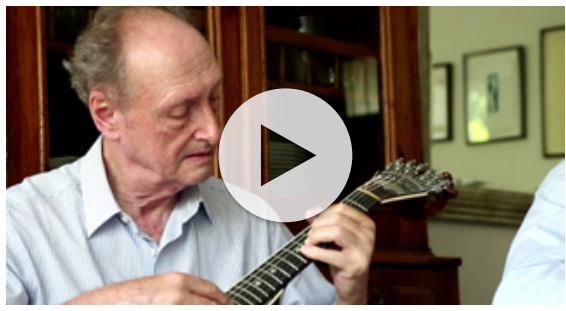

OS MEUS OLHOS SÃO DOIS CÍRIOS

Linhares Barbosa, Fado Menor

(LISA/USP, 3', 2017)

imagem e som: Rose Satiko Hikiji

edição: Leo Fuzer

senha do link: fado2017

figura 7

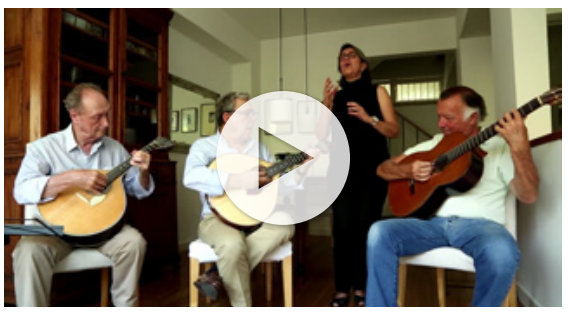

SONHO ANTIGO

Pedro Fortes Figueira, Fado Corrido

(LISA/USP, 3', 2017)

imagem e som: Rose Satiko Hikiji

edição: Leo Fuzer

senha do link: fado2017

Permitam-me um parêntesis, para dizer que o "Menor" e o "Corrido" fazem parte de uma "tríade" famosa, juntamente com o "Mouraria" (figura 8) - uma espécie de trindade fadista.

figura 8

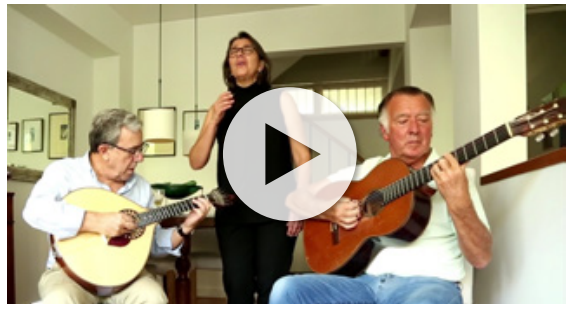

O MEU AMOR ANDA EM FAMA

João Ferreira Rosa, João Mário Veiga, Fernando Pessoa, Carlos Conde, Fado Mouraria (LISA/USP, 3', 2017) imagem e som: Rose Satiko Hikiji edição: Leo Fuzer

senha do link: fado2017

São fados predominantemente em dois tons, dos mais básicos do repertório fadista de todos os tempos. O "Mouraria" é o preferido para improvisar despiques entre fadistas, para cantar "à desgarrada". Dada a facilidade da estrutura musical destes três fados (permitindo que sejam acompanhados por qualquer músico, ou mesmo apenas à viola) e servidos por letras "em quadra" (a forma poética mais popular), tornaram-se "referência obrigatória" para todos os intervenientes no "ato fadista - cantores/declamadores, músicos, público. Ainda hoje, apesar do seu carácter extremamente elementar, que nos remete diretamente aos primórdios do fado, uma noitada fadista sem o "Menor", o "Corrido" ou o "Mouraria” é absolutamente improvável. 
Fechado o parêntesis, diga-se que nesse passado longínquo associavam-se ao fado o tabaco, o vinho, a voz áspera e rouca. 0 fado, mais que qualquer coisa que se cantava, era sobretudo algo que se contava e improvisava.

Os vários acontecimentos políticos de projeção nacional que ocorreram nas últimas décadas do século XIX, passando pela queda da monarquia e implantação da República em 1910, resultaram em importantes transformações a nível nacional e também na cidade de Lisboa.

Surge, por exemplo, uma classe operária emergente que começa a demarcar-se dos grupos mais pobres da população, querendo mostrar a sua identidade e diferença.

Os espaços e as situações de encontro multiplicam-se e o fado aparece como um veículo de sociabilidade.

O Fado é absorvido por esta nova classe emergente, não apenas como pretexto de encontro entre as pessoas, mas também como uma forma de contar a sua vida, assumindo uma forma de crítica social e moral (por exemplo, valorizando o contraste entre ricos e pobres, entre justos e injustos).

Segundo Nery (2012, resumo):

Quando a aristocracia boémia e as classes médias urbanas "redescobrem" este género, nas décadas de 1860 e 70, o Fado passa a ter lugar no teatro musical ligeiro, começa a ser publicado em edições de folhetos para uso doméstico e acabará por se tornar num favorito da indústria discográfica nascente.

o gosto pelo fado sai, assim de um grupo muito específico e marginal para se generalizar, começando a aparecer em pequenas publicações, festas de beneficência etc.

figura 9 Nery $(2004,81)$

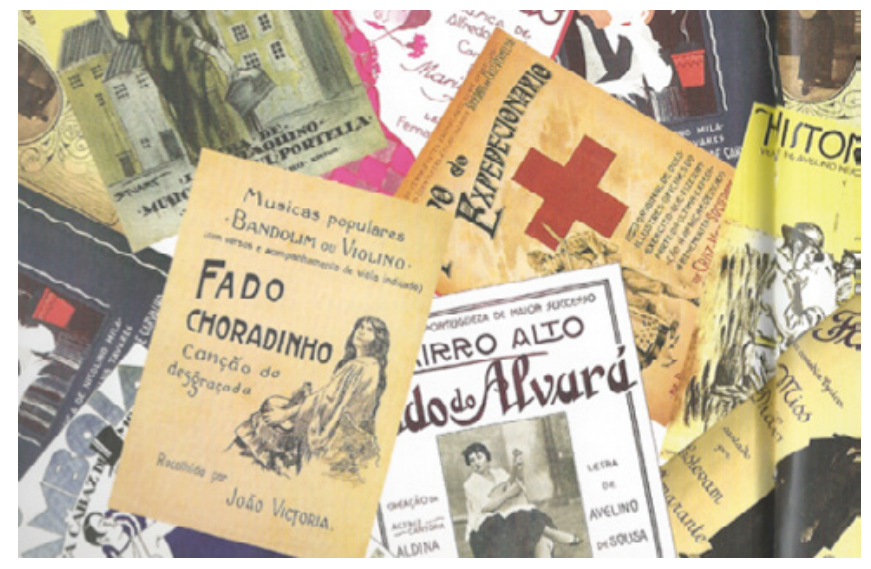


Desde o fim do século XIX até ao início do século XX assiste-se à proliferação de lugares e situações onde o fado se produz: entre eles, predominam tavernas, sociedades culturais e recreativas. Mas as suas grandes transformações aparecerão com o regime político instaurado pelo golpe militar de 1926, que termina com a Primeira República e marca o início da ditadura.

O regime impõe a censura prévia, estabelecendo leis no que diz respeito às condições de exibição pública e os lugares onde o fado poderia acontecer. As letras cantadas pelos fadistas eram censuradas pela autoridade estabelecida.
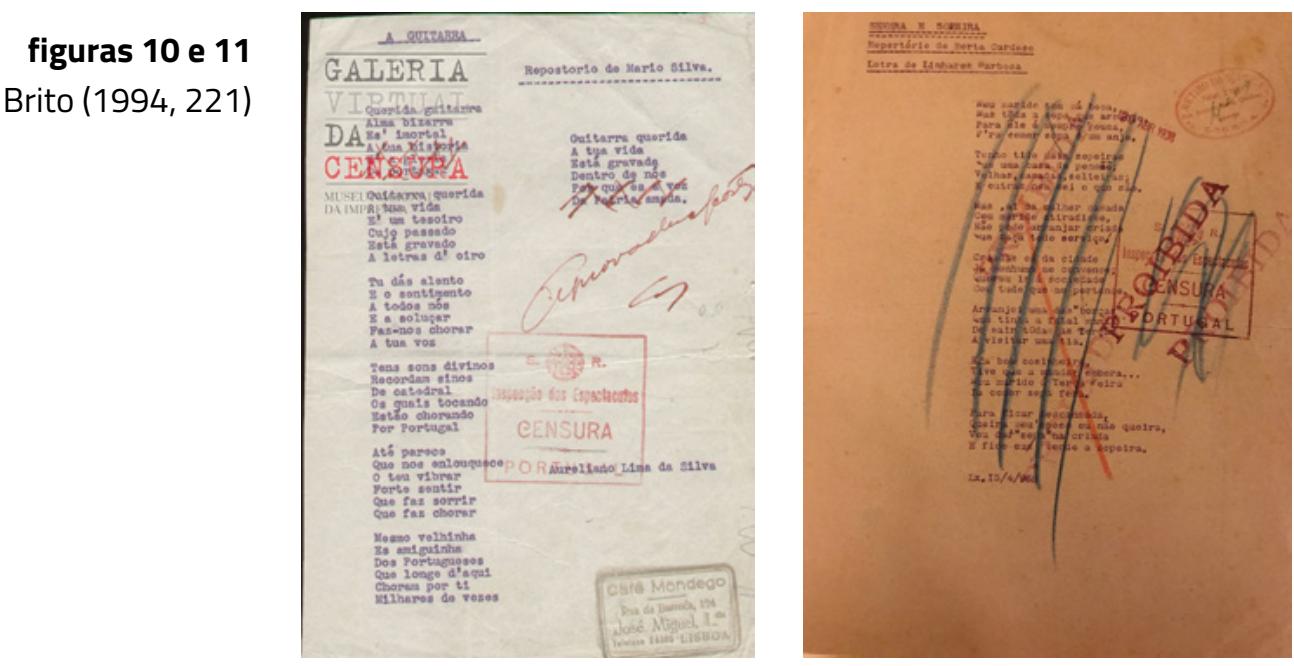

Os fadistas eram obrigados a ter uma carteira profissional para cantarem em público. Para obtê-la, era necessário provar que não tinham antecedentes criminais.

figura 12

Brito $(1994,95)$

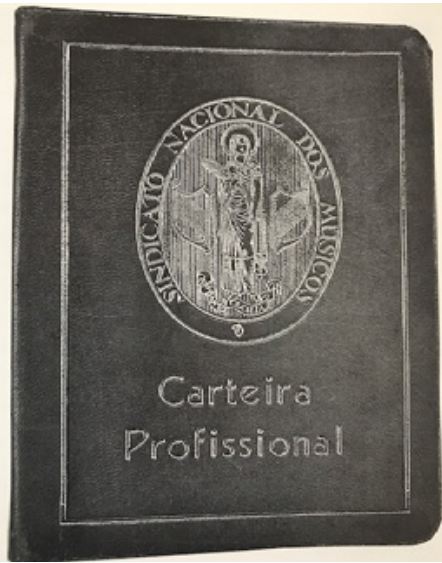


o fado perde, assim, a sua espontaneidade, as suas características, o seu estilo de improvisação, passando de um gesto quotidiano para um espetáculo cheio de limitações e regras.

A rádio, mais que contribuir para a proliferação dessa música, induziu as formas mais subtis de censura, fazendo uma triagem das vozes e formas de cantar consideradas socialmente aceites pelo regime. A censura reina de forma absoluta.

Paralelamente, a repressão aumenta, assim como a acção da polícia em relação aos locais onde se cantava o fado, limitando-o às casas de fado ou a restaurantes especializados e demasiado homogeneizados.

o fado separa-se, assim, dos grupos marginalizados onde nasceu, para se constituir como uma forma de manifestação estável e institucionalizada muito bem aceite pela ditadura.

Uma das consequências da passagem do "fado-quotidiano" para o "fado-espetáculo" foi a forma como os fadistas começaram a vestir-se. No passado, a imagem não tinha nenhuma importância. A partir do momento que se transforma em espetáculo, os fadistas começam a vestir-se com pompa e o xaile colorido passa a ser um adereço fundamental de qualquer mulher que cantasse o fado.

É nesse contexto, em plena ditadura, que aparece Amália Rodrigues (1920-1999). Se a ditadura impôs as transformações profundas nos locais e definiu quem podia cantar o fado, esvaziando-o de espontaneidade e improvisação, Amália Rodrigues foi sem dúvida o grande marco e quem mais revolucionou esta expressão musical portuguesa. Na minha opinião, partilhada por muitos, há um fado antes e outro após Amália.

Amália Rodrigues deu ao fado o preto como cor, os poemas e a voz. Ousou também cantar novas melodias que saíam completamente dos cânones tradicionais do fado. Saímos dos "fados-padrão" para a noção de "fado com música própria”. Estas melodias foram escritas, na sua maioria, pelo francês nascido em Portugal Alain Oulman (1928-1990) (figura 13).

figura 13

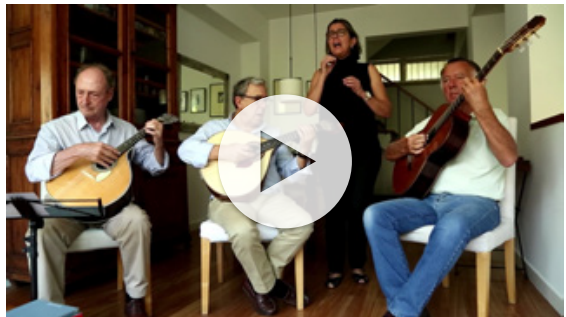

VAGAMUNDO

Luís de Macedo, Alain Oulman

(LISA/USP, 3', 2017)

imagem e som: Rose Satiko Hikiji

edição: Leo Fuzer

senha do link: fado2017 


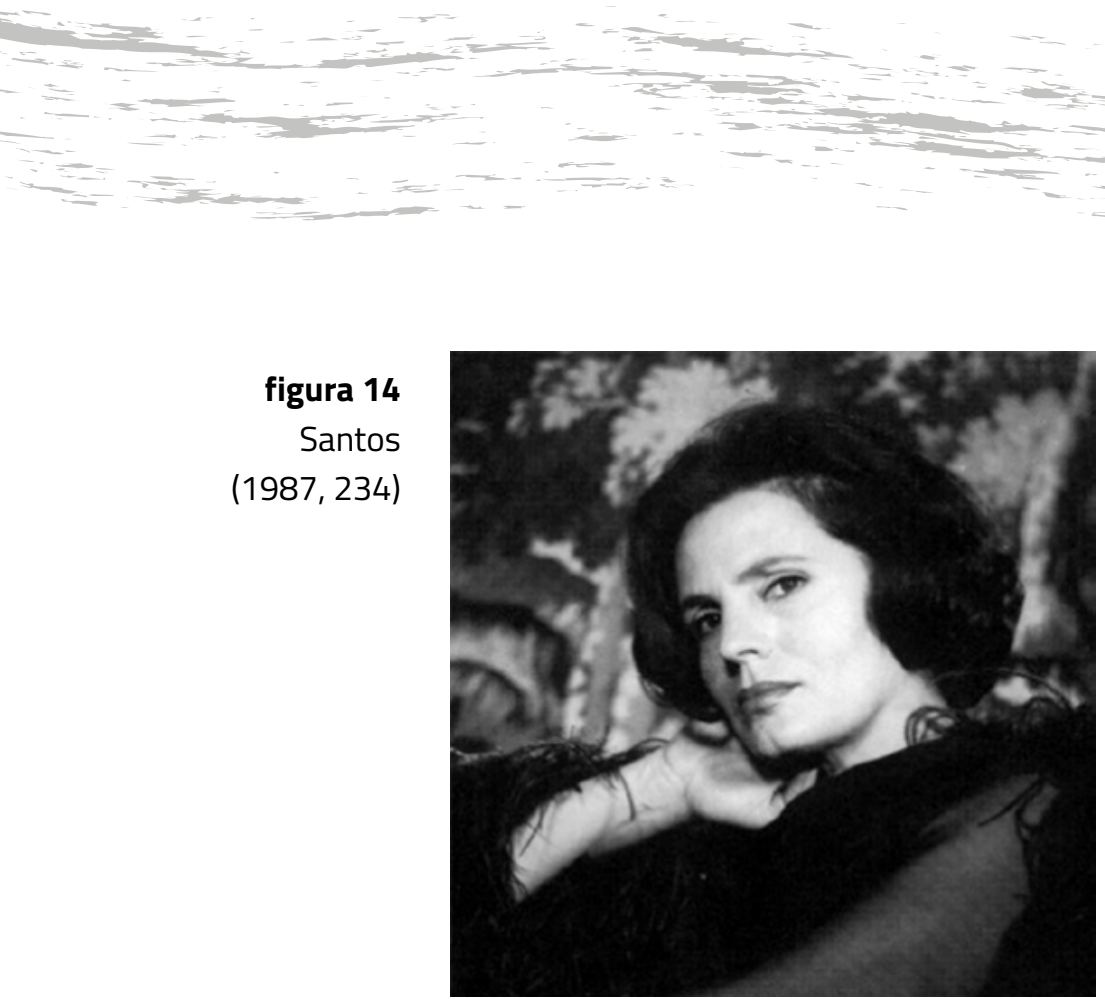

Amália é referência fundamental, porque ousou mudar e mudou quase tudo. Criticada pelos puristas sobre a sua forma de cantar - "à espanhola" ou "óperas" em vez de fados -, de tudo se ouviu, mas nada a fez parar e Amália venceu.

A partir dos anos 1950, Amália Rodrigues começa a cantar os poemas dos grandes poetas da literatura portuguesa. De Luís de Camões aos poetas eruditos do seu tempo: David Mourão Ferreira, Pedro Homem de Mello, Alexandre O’Neill, entre outros. Também cantou Vinícius de Moraes. 0 poema assume um estatuto que nunca teve antes na história do fado.

Amália, com a sua nova forma de cantar, fez um sucesso imenso e a ditadura faz do fado - e sobretudo de Amália Rodrigues - um cartão de visita do país no exterior. Razão pela qual após a queda da ditadura, em 25 de abril de 1974, o fado e Amália Rodrigues foram tão criticados, já que para muitos portugueses eram a imagem do regime. Hoje essa questão circunstancial está completamente afastada: a imagem do fado foi recuperada, assim como a de Amália Rodrigues.

A partir da década de 1990, surge uma geração de fadistas com significativa projeção nacional e internacional. Porque a força do mercado é omnipresente e tudo precisa ser catalogado para ser vendido, essa geração passou a pertencer à categoria da World Music, sendo o fado uma presença quase obrigatória em eventos assim classificados. Em 2011, o Fado foi declarado Património Imaterial da Humanidade pela UNESCO.

o fado que escutamos hoje em dia perdeu bastante o seu carácter narrativo, de descrição dos aspetos do quotidiano ou contraditórios da sociedade. Constatamos que a intenção de uma conclusão moral "final" também desapareceu. o que resta é um lamento, um murmúrio, a iminência de uma lágrima, uma dor representada, uma alegria, uma exultação, uma forma de sentir partilhada por quem interpreta, acompanha ou assiste. 


\section{UMA NOITE DE FADOS}

o fado, quando cantado, espera o silêncio e a cumplicidade de quem escuta. Quando há ruído na sala, ouve-se com frequência a chamada de atenção: "é tão fadista quem canta como quem ouve!"; ou "silêncio que se vai cantar o fado!". Para quem o canta, é mais importante o silêncio conseguido na sala do que os aplausos após a prestação. Essa característica ritual faz da performance do fado um ato coletivo de tipo celebratório. É nesse sentido que podemos também falar de partilha emocional, mais que de arte espetacular.

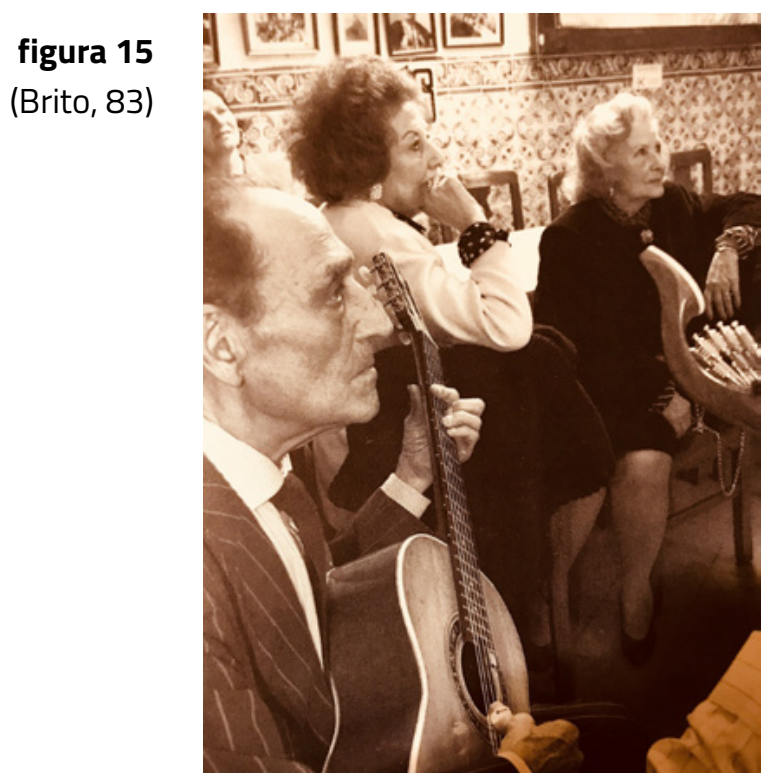

Nas casas de fado não há amplificação de som. Canta-se "a seco". o silêncio é fundamental para a emoção que o fadista exprime no momento, mas também para que seja possível escutar os instrumentos que acompanham a voz e possibilitar este diálogo entre a voz e as guitarras.

o Fado é tradicionalmente acompanhado por dois instrumentos, a viola e a guitarra portuguesa, assumindo esta um papel fundamental. A guitarra portuguesa, para quem não conhece, é uma muito provável evolução da guitarra inglesa, entretanto desaparecida. Introduzida em Portugal a partir das colónias de ingleses de Lisboa e do Porto, a guitarra inglesa conheceu uma grande divulgação nos salões europeus de meados do século XVIII. Em forma de pera, derivada da cítara, essa guitarra compunha-se de dez cordas, agrupadas em quatro pares, mais duas cordas soltas. De utilização exclusiva nos círculos da burguesia e da nobreza dos salões urbanos, é associada ao acompanhamento de cançonetas italianas de carácter mais erudito. 
figura 16

Nery $(2004,33)$

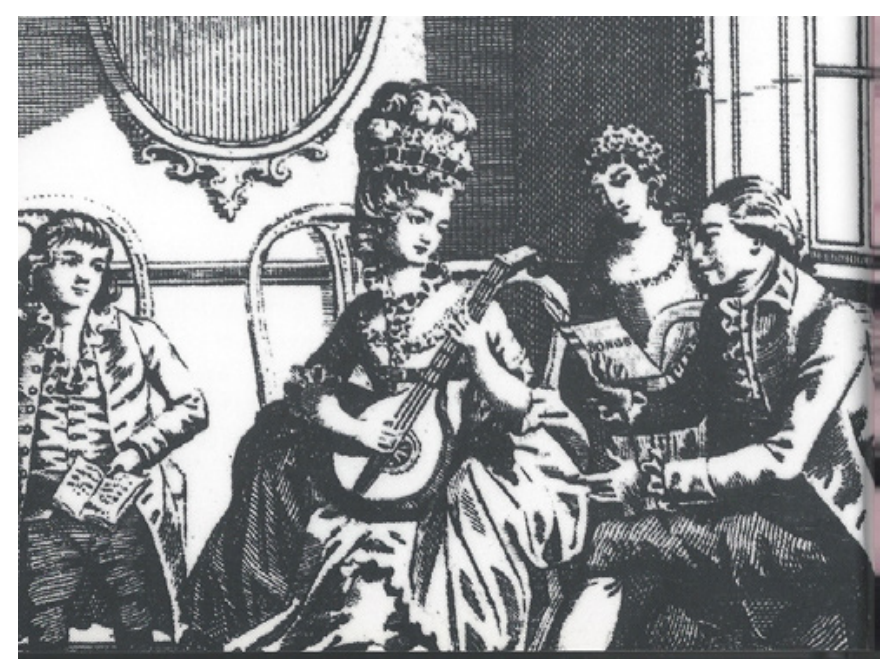

A partir do início do século XIX surge nas fontes históricas a designação de "guitarra portuguesa", que se refere ao modelo de seis pares de cordas, uma alteração provavelmente introduzida em Portugal. Sobretudo a partir de 1840 há notícias da sua associação ao contexto performativo fadista, em que assumirá um papel de absoluta centralidade.

figura 17

Brito $(1994,189)$

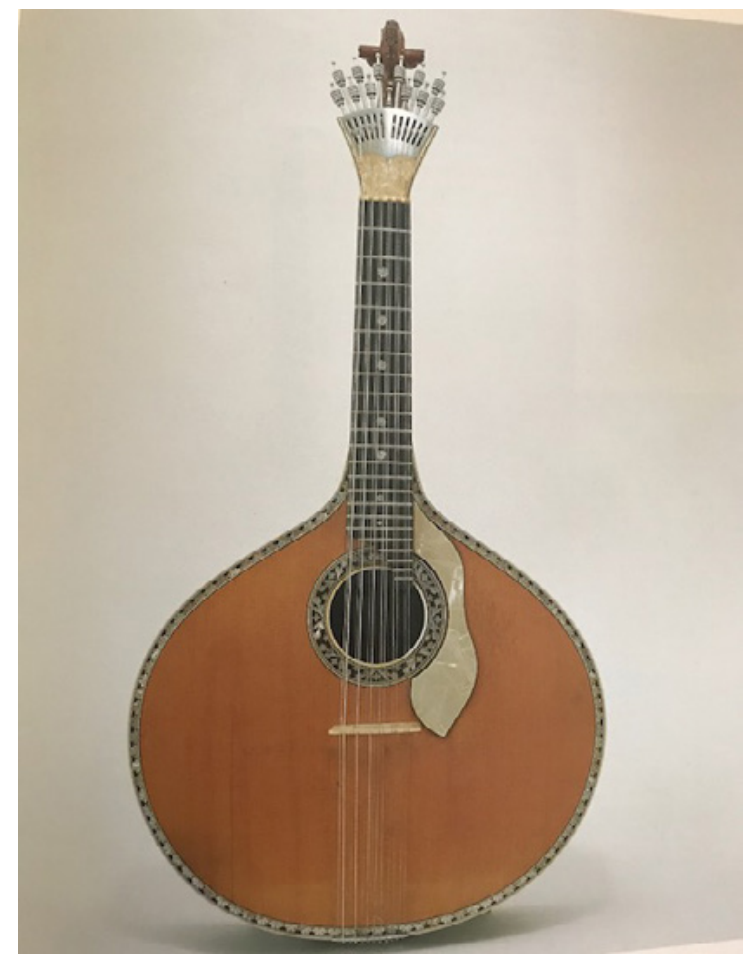

Por vezes, o baixo acústico e, mais recentemente, o contrabaixo poderão estar presentes numa sessão de fados. 
A viola dá a base rítmica e harmónica, e a guitarra portuguesa improvisa frases sustentadas por ricas harmonias, dialogando assim com a voz. Raramente a guitarra portuguesa toca do mesmo modo o mesmo fado. É necessário não esquecer que só muito recentemente surgiram algumas partituras escritas e, mais importante, apenas na viragem do milénio a guitarra portuguesa teve o direito de entrar no Conservatório Nacional, em Lisboa, com o mesmo estatuto que os restantes instrumentos musicais aí ensinados. Até então, era um instrumento popular desvalorizado e associado apenas ao fado. Quem contribuiu de forma apaixonada e exímia para a valorização da guitarra portuguesa como instrumento autónomo foi Carlos Paredes (1925-2004), que correu o mundo com a sua guitarra portuguesa e as suas composições instrumentais originais ${ }^{1}$.

figura 18

O Fado do

Público (2004, $\left.\mathrm{CD} \mathrm{n}^{\circ} 16,49\right)$

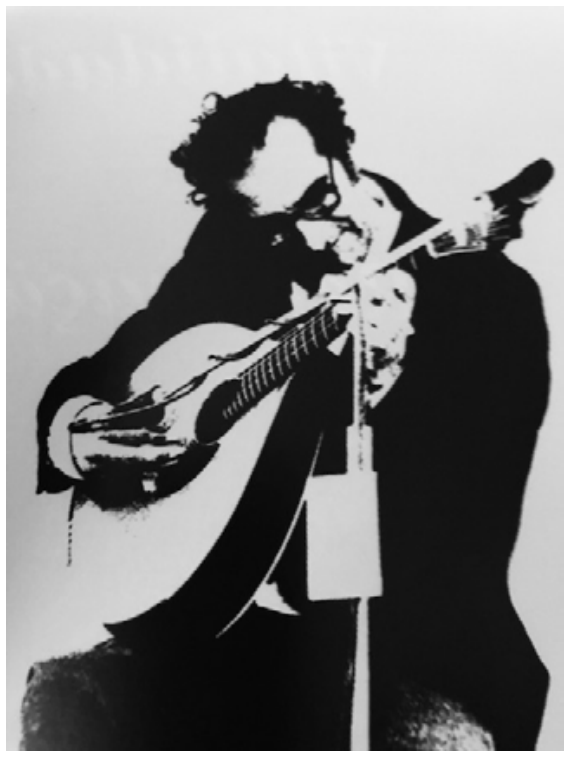

O gosto pelo fado por parte das camadas mais jovens (mas também por parte dos fadistas e instrumentistas mais velhos) permite que este género musical continue a acontecer de forma livre e improvisada, um pouco como sucede com certas vertentes do tango, do blues, ou do flamenco.

Existe uma grande oferta de casas de fado em Lisboa, algumas necessariamente voltadas ao consumo dos turistas - onde não há grande lugar para a improvisação -, outras em que o fado acontece de forma livre e verdadeira - as casas do chamado "fado vadio". Isso quer dizer que há músicos residentes (um guitarra e um viola). Normalmente há um(a) fadista contratado(a) pela casa e, depois, os clientes, vizinhos e amigos da casa que gostam de cantar o fado inscrevem-se/pedem para cantar, sempre com certa triagem feita pelo dono da taberna, do restaurante ou da casa.

1 Disponível em https:/goo.gl/YmBgW5 acessado em 4/12/2017. 
E como é possível que nesses ambientes o fado possa acontecer sem que, muito frequentemente, os fadistas e músicos se conheçam, sem ensaios, sem preparação prévia?

A razão é que o fado de Lisboa tem pelo menos 150 melodias/fados chamados tradicionais - o fado "Tango", o "Margaridas", o "Sem Pernas", o "Maria Vitória", o "Santa Luzia", o "Alberto", etc. Em princípio, um bom guitarrista deve conhecê-los todos e em todos os tons. Lembremos que uma boa parte das melodias do fado tradicional são simples. É, sobretudo, a interpretação de quem canta e o diálogo com os músicos que lhe confere riqueza.

Dessa forma, quando é chamado, o fadista dirige-se aos músicos e pede, por exemplo, o fado "Alberto" em lá, ou o fado "Georgino" em mi. Tem que dizer se o ritmo é lento ou "picado" (rápido). o fadista põe o poema que entende e que gosta de cantar. Pode ser um poema erudito ou popular (figura 19). Numa só noite de fados podemos ouvir a mesma melodia cantada várias vezes, com poemas e interpretações diferentes. É preciso ser um razoavelmente bom conhecedor do fado para detetar que se trata da mesma melodia, do mesmo fado.

figura 19

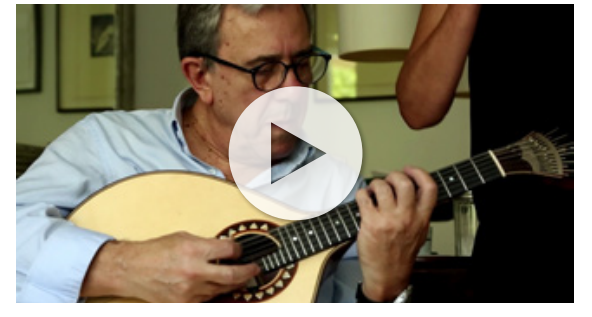

NÃO PASSES COM ELA À MINHA RUA/QUASE Carlos Conde (poeta popular) e Quase, Mário de Sá Carneiro (poeta erudito), Fado Alberto (Miguel Ramos)

(LISA/USP, 5', 2017)

imagem e som: Rose Satiko Hikiji

edição: Leo Fuzer

senha do link: fado2017

Normalmente, cada fadista canta três ou quatro canções e fazem-se vários intervalos durante a noite para que as pessoas possam falar e os clientes sejam servidos, porque, enquanto se canta o fado, o silêncio absoluto deve reinar. Mais uma vez o dono da casa tem um papel fundamental de controle e exigência desse silêncio. Também o público mais atento e experiente não hesitará em mandar calar se houver alguém que perturbe a performance.

Os fados "com música própria”, que Amália Rodrigues e Alain Oulman introduziram - e que são muito frequentes nos fadistas das gerações mais jovens - são raramente tocados nesse tipo de ambiente. São fados cuja melodia é mais elaborada, mais difícil de transpor e pressupõem ensaio, o que não é compatível com o ambiente onde o fado vadio acontece.

Esse modo de cantar o fado que assim se instalou, em que a improvisação tem um papel fundamental, faz com que, por vezes, haja noites de relativo insucesso, mas outras absolutamente gloriosas. Não foram 
poucas as vezes que entrei numa casa de fados onde se começou a cantar às 10 horas da noite, só se terminando às 4 ou 5 horas da manhã. Os dedos dos guitarristas resistem dificilmente nessas circunstâncias, apesar do hábito de tocarem todos os dias.

\section{PARA TERMINAR...}

Não é impossível uma dança converter-se numa canção. E, muito provavelmente, isso terá acontecido com o fado. É, pois, no mínimo legítimo interrogar como uma dança terá ganho foros de canção num contexto urbano (Lisboa) atravessado de múltiplas formas musicais tradicionais. Ou como a base musical de uma coreografia sincopada pode estar na origem da musicalidade do fado.

o fado terá, pois, um "princípio, meio e fim" em que se cruzam as músicas presentes nos bairros populares lisboetas dos séculos XVIII e XIX. É isso que poderemos designar por "musicalidade fadista".

A fixação dessa musicalidade naquilo a que chamaríamos um "género", é um longo processo em que cada "conto acrescenta um ponto". Ou, se quisermos, em que "cada fadista acrescenta um fado", ou "cada guitarrista acrescenta uma melodia ou uma harmonia".

A musicalidade fadista de hoje talvez seja uma combinação de todos os factores que lhe foram adicionados e multiplicados desde há mais de dois séculos. o quadro musical a que hoje chegámos é o fruto dessa pluralidade criativa.

Poderemos tentar definir as regularidades, os padrões harmónicos, a estrutura rítmica, e certamente nos confrontaremos com algo reconhecível numa unicidade. Mas também é verdade que várias outras formas musicais poderiam convergir no fado por essas mesmas características. Talvez seja devido a isso que muitas canções são facilmente "afadistáveis".

o contexto ritual fadista compõe a outra parte do fado - aquela em que mesmo quem não canta e quem não toca guitarra participa voluntariamente, adoptando o mesmo registo cultural dos artistas. "É tão fadista quem canta como quem ouve", dissemos atrás.

O silêncio, que é um sinal tão forte da performance fadista, poderá ter sido uma das formas de o ritualizar.

De início declamado ou cantado em ambientes "naturalmente" muito barulhentos (como a taberna), não seria surpreendente que quem quisesse compreender a história contada pelo fado pedisse menos barulho (ou mesmo silêncio). 
Não me surpreenderia, pois (mas é apenas um palpite sem qualquer fundamento científico), que essa fosse uma das características da "cristalização dinâmica" de vários elementos em torno daquilo a que se convencionou chamar fado nos seus primórdios.

o silêncio é, na minha opinião, peça-chave na musicalidade do género. Sem silêncio não acontece fado.

Silêncio que se vai cantar o fado...!

\section{REFERÊNCIAS BIBLIOGRÁFICAS}

Brito, Joaquim Pais de (ed.). 1994. Fado: Vozes e Sombras. Lisboa: Museu Nacional de Etnologia.

Bocage, Manuel Maria Barbosa du. 1968. Obras de Bocage. Porto: Lello \& Irmão - Editores

Camões, Luís de. 1994. Lírica Completa II. Lisboa: Imprensa Nacional - Casa da Moeda.

Nery, Rui Vieira. 2004. Para uma História do Fado. Lisboa: Público.

Nery, Rui Vieira. 2012. Palestra sobre a história do fado pelo Prof. Doutor Rui Vieira Nery. Blogue Camões, 23 nov. 2012. Disponível em: https://goo.gl/9HjJhc

Nicolay, Ricardo. 2012. O fado de Portugal, do Brasil e do Mundo: as teorias sobre a sua origem. Revista Contemporânea, vol. 10, no. 2: 58-70.

Santos, Vítor Pavão dos. 1987. Amália: uma biografia. Lisboa: Contexto.

\section{REFERÊNCIAS AUDIOVISUAIS}

O Fado do Público - 100 anos de Fado - 20 CDs/Volumes. 2004. Lisboa: Corda Seca Edições de Arte, SA, Público, SA.

Os meus olhos são dois círios - Linhares Barbosa/Fado Menor. Imagem e som: Rose Satiko Hikiji. Edição: Leo Fuzer. LISA/USP, 2017, 3 minutos - Disponivel em: https://vimeo.com/lisausp/meusolhossaodoiscirios

Sonho antigo - Pedro Fortes Figueira/Fado Corrido. Imagem e som: Rose Satiko Hikiji. Edição: Leo Fuzer. LISA/USP, 2017, 3 minutos - Disponivel em: https://vimeo. com/lisausp/sonhoantigo

O meu amor anda em fama - João Ferreira Rosa/João Mário Veiga/Fernando Pessoa/Carlos Conde/ Fado Mouraria. Imagem e som: Rose Satiko Hikiji. Edição: Leo Fuzer. LISA/USP, 2017, 3 minutos - Disponivel em: https:/vimeo.com/lisausp/meuamorandaemfama 
Vagamundo - Luís de Macedo/Alain Oulman. Imagem e som: Rose Satiko Hikiji. Edição: Leo Fuzer. LISA/USP, 2017, 4 minutos - Disponível em: https://vimeo.com/ lisausp/vagamundo

Movimento perpétuo - Carlos Paredes - Disponível em: https://goo.gl/YmBgW5

Não passes com ela à minha rua - Carlos Conde (poeta popular) e Quase - Mário de Sá Carneiro (poeta erudito)/ Fado Alberto (Miguel Ramos). Imagem e som: Rose Satiko Hikiji. Edição: Leo Fuzer. LISA/USP, 2017, 5 minutos - Disponível em: https://vimeo.com/lisausp/quase

\section{CRISTINA ROSAL}

recebido Cristina Rosal, portuguesa, nascida em Moçambique em 1960, licenciada em Sociologia pelo Instituto Universitário de Lisboa (ISCTE), vivendo em Bruxelas, Bélgica. Funcionária internacional (União Europeia), cantadeira quando a alma reclama e amante de fado. 